\title{
Graphene oxide prepared by a room temperature oxidation using a green mechanochemical method
}

G. Tarango-Rivero ${ }^{1}$, G. Herrera-Perez ${ }^{2}$, C. Carreño-Gallardo ${ }^{1}$, C.G. Garay-Reyes ${ }^{3}$, I. Estrada-Guel ${ }^{3}$ and R. Martínez-Sánchez ${ }^{4}$

${ }^{1}$ Centro de Investigación en Materiales Avanzados (CIMAV), Chihuahua, Chihuahua, Mexico, ${ }^{2}$ Centro de Investigación en Materiales Avanzados, Chihuahua, Chihuahua, Mexico, ${ }^{3}$ Centro de Investigación en Materiales Avanzados (CIMAV), Laboratorio Nacional de Nanotecnología, Miguel de Cervantes No. 120, CP 31136, Chihuahua, Chih., México., Chihuahua, Chihuahua, Mexico, ${ }^{4}$ Centro de Investigación en Materiales Avanzados (CIMAV) Laboratorio Nacional de Nanotecnología, Miguel de Cervantes No. 120, CP 31136, Chihuahua, Chih., México., Chihuahua, Chihuahua, Mexico

Carbon structures as graphene, nanotubes, nano-onions, nano-diamonds, and others have been deeply studied for a wide variety of applications in some potential fields [1]. Graphene (G) is a nanostructured carbon that is the focus of attention of some researching groups since it was first prepared from graphite (Gr) separation in 2004. The original procedure is simple and economical but is not suitable for largescale production. Other routes used to obtain $\mathrm{G}$ and graphite oxide $(\mathrm{GrO})$ have high operative costs. The wet chemical method is low-cost and scalable but not sustainable due to the imperative consumption of dangerous chemicals for graphite oxidation. There is an ongoing need for affordable production methods to obtain commercial quantities of $\mathrm{G}$ or $\mathrm{GrO}$ with green chemistry principles using non-toxic chemicals or environmentally friendly solvents. A practical route to fulfill these requirements can be achieved by dry solvent-free processing based on high-energy ball milling, which can easily modify the chemical reactivity of the milled solids, inducing chemical reactions during milling [2]. For this experimentation, $16 \mathrm{~g}$ of natural $\mathrm{Gr}$ were processed in a planetary mill (Pulverisette-Fritsch) using a ball to powder weight ratio of 5:1 in a hardened steel vial for $8 \mathrm{~h}$ in an inert atmosphere (Ar). GrO was obtained simply by putting the fresh milled powder in contact with air. This simple operation can introduce functional groups at the edges, surfaces, and basal planes in the highly activated milled material [3]. To observe the morphological characteristics and oxygen present in the samples, SEM-EDS studies were performed in a JSM-7401F microscope. Some supplementary information related to structural changes in milled samples was obtained by X-ray photoelectronic spectroscopy (XPS); this technique has been advantageously used for studying carbon structures, clarifying the nature of specific carbon bonds.

Fig. 1 shows two SEM micrographs of the samples with their corresponding chemical analyses before and after milling. The sample morphology changes; the natural $\mathrm{Gr}$ has a flake shape and larger particle size. After milling, we can notice the formation of rounded particles with a homogenous size. This marked size reduction increases the powder chemical reactivity. The Gr reacts with the atmospheric oxygen at room temperature without harmful chemical necessity, increasing its oxygen content from 0 to $6 \%$, as shown in the EDS analyses. Fig. 2a shows the zone $\mathrm{C} 1 \mathrm{~s}$ of the natural graphite, it is observed a peak at $284.83 \mathrm{eV}$ which indicates the presence of a main sp2 hybridization (from $\mathrm{C}-\mathrm{C}$ or $\mathrm{C}-\mathrm{H}$ bonding), indicating a planar hexagonal structure characteristic of Gr. In Fig. 2b, it is observed a peak at 284.77 corresponding to sp2 carbon coupled with some characteristic peaks of hydroxyl $(\mathrm{C}-\mathrm{OH})$, ether/esters $(\mathrm{C}-\mathrm{O}-\mathrm{C})$ and epoxy $(\mathrm{O}-$ $\mathrm{C}=\mathrm{O}$ ) compounds. The pure planar graphitic structure is partially lost and some 3D tetrahedral structures appear in the milled sample. This evidence supports the oxidation supposition observed through SEMEDS; these XPS peaks are commonly referred on the literature as GO formation indication. 

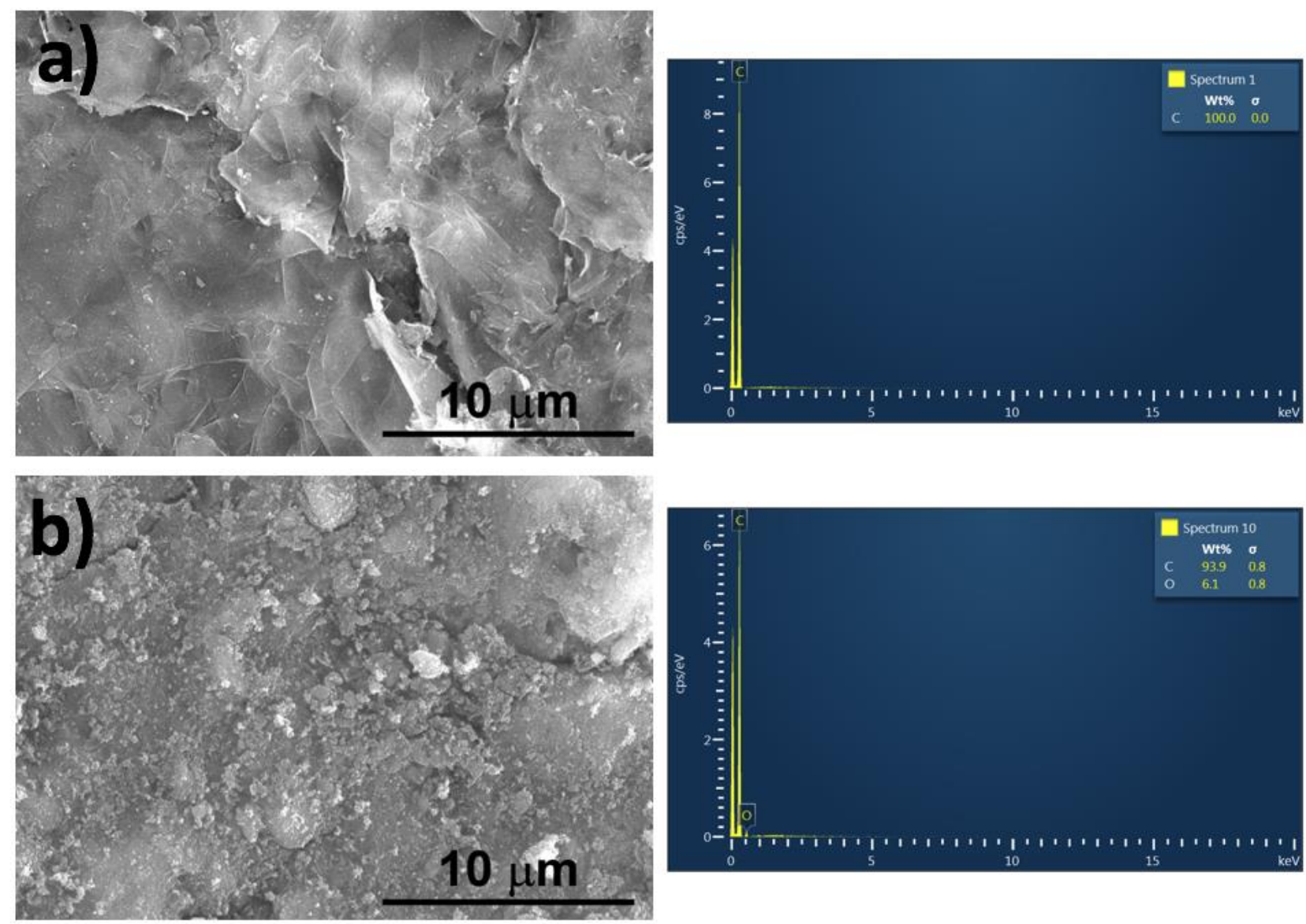

Figure 1. SEM images and chemical composition of a) original and b) $8 \mathrm{~h}$ milled samples.
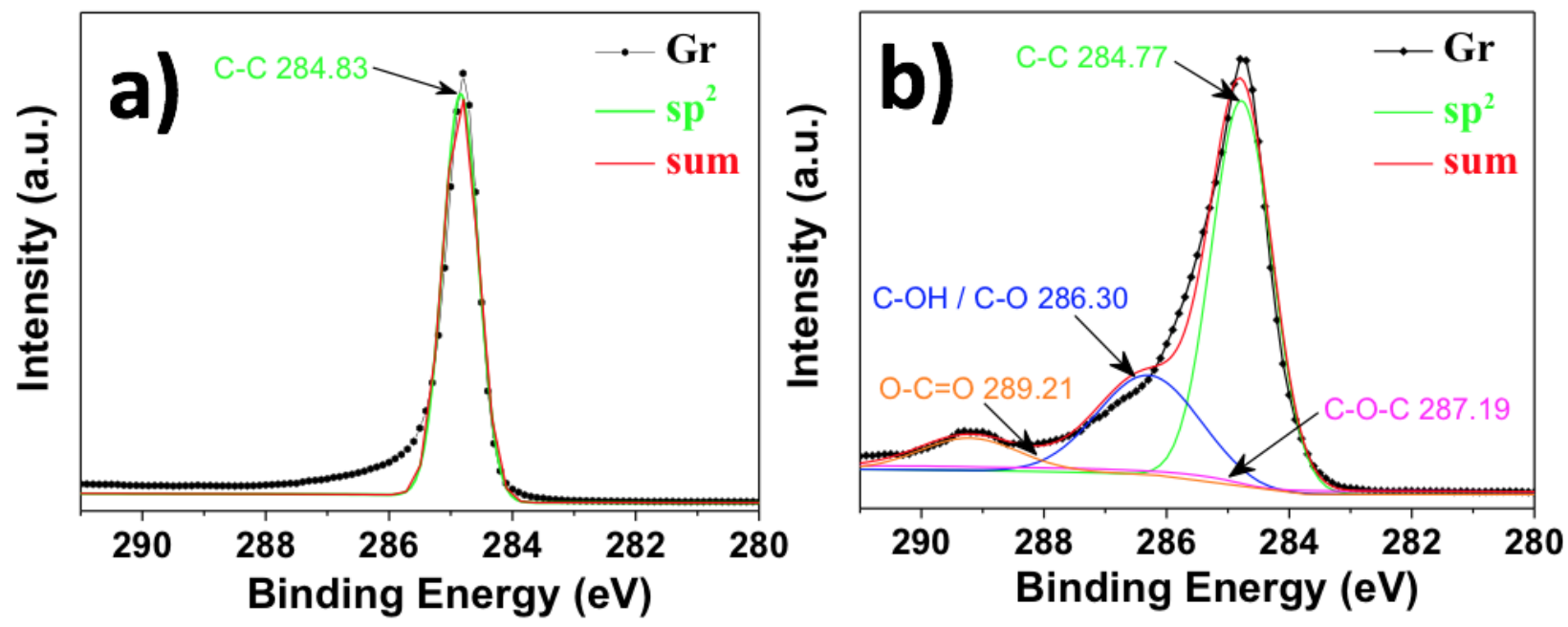

Figure 2. XPS spectra of a) original and b) $8 \mathrm{~h}$ milled samples.

References 
[1] D. Codorniu Pujals, D. Rodríguez Garcés, O. Arias de Fuentes, L. Desdín García, XPS of carbon nanostructures obtained by underwater arc discharge of graphite electrodes, Nucleus No 64, 2018.

[2] Weblink:http://www.understandingnano.com/nanomaterial-synthesis-ball-milling.html.

[3] A. Mahmoud, A. Stolle, M. Stelter, Sustainable Synthesis of High-Surface-Area Graphite Oxide via Dry Ball Milling, ACS Sustainable Chem. Eng. 2018, 6, 6358-6369. 